\title{
Emerging B-Cell Therapies in Systemic Lupus Erythematosus
}

This article was published in the following Dove Press journal:

Therapeutics and Clinical Risk Management

\author{
Ayse Bag-Ozbek' \\ Joyce S Hui-Yuen ${ }^{2-4}$
}

'Division of Rheumatology, Renaissance School of Medicine, Stony Brook University Medical Center, Stony Brook, NY, USA; ${ }^{2}$ Division of Pediatric Rheumatology, Steven and Alexandra Cohen Children Medical Center, New Hyde Park, NY, USA; ${ }^{3}$ Zucker School of Medicine at Hofstra/Northwell, Hempstead, NY, USA; ${ }^{4}$ Center for Autoimmune, Musculoskeletal, and Hematopoietic Diseases Research, Feinstein Institute for Medical Research, Manhasset, NY, USA
Correspondence: Joyce S Hui-Yuen Division of Pediatric Rheumatology, Steven and Alexandra Cohen Children Medical Center, 1991 Marcus Avenue, Suite MI00, New Hyde Park, NY I I040, USA

Tel + I 516.472 .3700

$\mathrm{Fax}+\mid$ 516.472.3752

Email jhuiyuen@nshs.edu

\begin{abstract}
Systemic lupus erythematosus (SLE) is a chronic, multisystem, autoimmune disease of unknown etiology, whose hallmark is the production of autoantibodies. B cells are promising targets for novel SLE therapies. In 2011, belimumab (Benlysta ${ }^{\circledR}$ ), a fully humanized monoclonal antibody inhibiting B-cell activation and proliferation, was the first medication in 50 years to be approved by the US Food and Drug Administration to treat adult SLE. This review discusses the current experience with B-cell-targeted therapies, including those targeting B-cell-surface antigens (rituximab, ocrelizumab, ofatumumab, obinutuzumab, obexelimab, epratuzumab, daratumumab), B-cell survival factors (belimumab, tabalumab, atacicept, blisibimod), or B-cell intracellular functions (ibrutinib, fenebrutinib, proteasome inhibitors), for the management of SLE. It focuses on ongoing clinical trials and real-world post-marketing use, where available, including their safety profiles, and concludes with our recommendations for B-cell-centric approaches to the management of SLE.
\end{abstract}

Keywords: systemic lupus erythematosus, treatment, novel B-cell therapies, belimumab, rituximab, epratuzumab

\section{Introduction}

Systemic lupus erythematosus (SLE) is a chronic systemic autoimmune disease of unknown etiology, affecting predominantly women of reproductive age with an affected female-to-male ratio of 9:1. ${ }^{1}$ It is clinically heterogeneous, can affect multiple organ systems, and is characterized by unpredictable periods of disease flare and remission. Despite the recent advances in SLE treatment, patients continue to experience significant morbidity and mortality. ${ }^{2-4}$ Physicians currently manage SLE with multiple immunosuppressive medications that can both improve disease control and also put patients at risk for severe side effects from broad immunosuppression. ${ }^{5,6}$ Also, SLE patients can develop disease flares despite what appears to be the optimal treatment. Thus, there remains a need for safer and more effective targeted therapies for treatment of SLE.

The hallmark of SLE is the production of autoantibodies by autoreactive B cells reacting to self-antigens and triggering an overwhelming inflammatory response. ${ }^{7}$ In healthy individuals, B cells help maintain a functioning immune system and produce protective antibodies. This mechanism appears to be altered in SLE patients, and may be enhanced by a paucity of, or abnormality in, other regulatory immune cells. ${ }^{8}$ Novel therapies have been and are currently in development targeting factors promoting growth, activation, and proliferation of B cells, as well as targeting specific surface molecules expressed across various B cell subpopulations to lead to their depletion, anergy, or apoptosis. ${ }^{9-20}$ 
Targeted immunosuppression may have beneficial outcomes for therapies in SLE. In particular, B cells and their various subpopulations have been shown to play a crucial role in the pathogenesis of SLE. B cells arise from the bone marrow and develop through several stages of maturation prior to producing antibodies as plasma cells. $B$ cells also express varied and different cell surface antigens at different stages of maturation ${ }^{7}$; CD20 and CD22 are B-cell-surface antigens expressed on immature and mature B cells, but not plasma cells. Immature and mature B cells are the precursors of plasma cells producing autoantibodies. They have other functions including the production of pro-inflammatory cytokines, and also regulate $\mathrm{T}$ cell activity via co-stimulation, making these surface antigens attractive for targeted therapy. ${ }^{7}$

It is widely theorized that SLE treatment failures after administration of agents targeting B-cell-surface antigens, such as CD20, may result from long-lived plasma cells that survive due to their lack of expression of CD20 on their cell surfaces. This led to alternative targets of B-cell activation, in particular survival and growth factors, including B lymphocyte stimulator (BlyS, also called B cellactivating factor BAFF) and proliferating-inducing ligand (APRIL), which are two members of the tumor necrosis factor (TNF) superfamily ${ }^{7,21}$ for treatment of SLE. Elevated levels of BlyS have been detected in sera of patients with SLE, ${ }^{22,23}$ and an association between serum BlyS levels and disease activity of SLE has been demonstrated, making BlyS an attractive target for therapy.

Intracellular signaling pathways to activate B cells during a pro-inflammatory response include those involving Bruton's tyrosine kinase (BTK); inhibition of BTK is currently being investigated for SLE therapy. ${ }^{19}$ Similarly, there is interest in the development of a proteasome inhibitor to specifically inhibit B-cell differentiation, through its toxic effect on plasma cells. ${ }^{20,24}$

Induction and maintenance of SLE disease remission is as important as prevention of chronic organ damage and drug-related morbidity. It continues to be difficult to measure the efficacy of novel therapies with a single disease activity or damage index. Thus, composite scores are used in many of the studies discussed in this review. The belimumab Phase III trials, ${ }^{9,10}$ introduced the SLE Responder Index 4 (SRI-4) that includes a reduction by 4 or more points on the SLE Disease Activity Index-2000 (SLEDAI-2K) scale, no more than $10 \%$ increase in the physician global assessment (PGA), no new organ involvement recorded with the British Isles Lupus Assessment
Group (BILAG) A score, and no more than 1 new BILAG B organ score. ${ }^{25}$

In this review, we will provide an overview of the efficacy and safety of rituximab, belimumab, other BlyS family inhibitors, and epratuzumab from the phase III trials. Real-world clinical experiences with these medications will be discussed, including use in refractory or below optimal treatment of SLE. We conclude with a discussion of current clinical trials investigating novel therapies under development, and our perspective and recommendations for the use of these B cell-centric therapies in our armamentarium to treat SLE.

\section{Ritixumab \\ Clinical Efficacy}

Rituximab is a chimeric monoclonal antibody depleting CD20-positive B cells, thereby sparing stem cells and plasma cells. ${ }^{26,27}$ Rituximab depletes $\mathrm{B}$ cells via antibody-dependent cell-mediated cytotoxicity (ADCC), complement-mediated cytotoxicity (CDC), apoptosis and antibody-dependent phagocytosis (ADP). ${ }^{28,29}$ It can induce the apoptosis of B cells, inhibit the proliferation of $\mathrm{B}$ cells, and effectively stop the abnormal proliferation of B cells. ${ }^{30}$ Rituximab is currently a therapeutic option to treat refractory SLE manifestations, including nephritis and neuropsychiatric disease. ${ }^{31-33}$ A large systematic review, including a total of 35 uncontrolled studies and case reports, showed that $91 \%$ of 188 SLE patients treated with rituximab demonstrated a significant improvement in at least one systemic SLE manifestation. ${ }^{34}$ Rituximab is not approved by the Food and Drug Administration (FDA) in the United States to treat systemic lupus.

Two randomized controlled trials were conducted to evaluate the use of rituximab to treat SLE: the Exploratory Phase II/III SLE Evaluation of Rituximab (EXPLORER) trial and the Lupus Nephritis Assessment with Rituximab (LUNAR) trial (Table 1). ${ }^{35,36}$ We have reviewed both these trials in-depth in another review. ${ }^{37}$ EXPLORER randomized 257 patients with moderate-tosevere extra-renal SLE in a 2:1 ratio to receive rituximab or placebo in addition to their baseline immunosuppressive agents and a 10-week course of moderate-to high-dose oral prednisone. LUNAR randomized 144 patients with new or relapsed biopsy-proven class III or IV proliferative lupus nephritis (LN) to receive placebo or rituximab and methylprednisolone, plus mycophenolate mofetil (MMF) and oral prednisone. Neither of these trials met their primary endpoints. EXPLORER did show that rituximab reduced the 
Table I B-Cell-Targeted Therapies for Treatment of Systemic Lupus Erythematosus

\begin{tabular}{|c|c|c|}
\hline Name of Medication and Mechanism of Action & $\begin{array}{l}\text { Significant } \\
\text { Trial/Study }\end{array}$ & Significant Findings \\
\hline \multirow[t]{3}{*}{$\begin{array}{l}\text { Rituximab: Chimeric anti-CD20 monoclonal antibody } \\
\text { (intravenous) }\end{array}$} & EXPLORER $^{35}$ & $\begin{array}{l}\text { Did not meet primary endpoint for treatment of moderate to } \\
\text { severe extra-renal SLE. Reduced risk and frequency of SLE } \\
\text { flares. }\end{array}$ \\
\hline & LUNAR $^{36}$ & $\begin{array}{l}\text { Did not meet primary endpoint for treatment of new or } \\
\text { relapsed class III or IV LN. Normalized complement levels, } \\
\text { proteinuria, and anti-dsDNA autoantibody levels. }\end{array}$ \\
\hline & $\begin{array}{l}\text { Cohort } \\
\text { studies }^{31,32,39,40}\end{array}$ & $\begin{array}{l}\text { Use of rituximab in NPSLE. Although patients demonstrated } \\
\text { improvement after treatment with rituximab, } 40-60 \% \\
\text { experience relapse within } 17 \text { months. }\end{array}$ \\
\hline \multirow[t]{4}{*}{$\begin{array}{l}\text { Belimumab: Human anti-BlyS monoclonal antibody } \\
\text { (intravenous or subcutaneous). Approved in the USA and } \\
\text { Europe for treatment of adult SLE in } 2011\end{array}$} & $\begin{array}{l}\text { BLISS-52 and } \\
\text { BLISS- } 76^{9,10}\end{array}$ & $\begin{array}{l}\text { International phase III trials for intravenous form. Met primary } \\
\text { efficacy endpoint for treatment of moderate-to-severe } \\
\text { seropositive SLE. Reduced disease activity/flares. Subgroup } \\
\text { analysis of trial patients with lupus nephritis demonstrated } \\
\text { some improvement leading to BLISS-LN. }\end{array}$ \\
\hline & BLISS-LN ${ }^{49}$ & $\begin{array}{l}\text { Met primary efficacy endpoint for treatment of active class III, } \\
\text { IV } \pm V L N \text { with intravenous form after induction therapy with } \\
\text { HDSC+MMF, or HDSC+CYC. }\end{array}$ \\
\hline & BLISS-SC ${ }^{45}$ & $\begin{array}{l}\text { Met primary endpoint for treatment of moderate-to-severe } \\
\text { seropositive SLE with subcutaneous form. Reduced flare rate } \\
\text { and able to taper steroid dose. }\end{array}$ \\
\hline & EMBRACE $^{47}$ & $\begin{array}{l}\text { Did not meet primary endpoint for treatment of SLE with } \\
\text { intravenous form in Black patients. }\end{array}$ \\
\hline $\begin{array}{l}\text { Approved for treatment of SLE in patients aged } 5-17 \text { years in } \\
2019\end{array}$ & PLUTO $^{46}$ & $\begin{array}{l}\text { Combined phase II/III trial in pediatric lupus using intra-venous } \\
\text { form. Over } 50 \% \text { of the children met the primary endpoint. } \\
\text { Able to taper steroid doses. }\end{array}$ \\
\hline Rituximab followed by belimumab & CALIBRATE $^{50}$ & $\begin{array}{l}\text { Did not meet primary endpoint for treatment of recurrent } \\
\text { refractory class III/IV } \pm V L N \text { using intravenous form. }\end{array}$ \\
\hline \multirow[t]{2}{*}{$\begin{array}{l}\text { Epratuzumab: Human anti-CD22 monoclonal antibody } \\
\text { (intravenous) }\end{array}$} & $\begin{array}{l}\text { ALLEVIATE-I } \\
\text { and } \\
\text { ALLEVIATE- }{ }^{69}\end{array}$ & $\begin{array}{l}\text { Phase III trials discontinued prematurely due to interruption in } \\
\text { supply of medication. }\end{array}$ \\
\hline & $\begin{array}{l}\text { EMBODY-I and } \\
-2^{14}\end{array}$ & Phase III trials that did not meet primary endpoints. \\
\hline
\end{tabular}

Abbreviations: BlyS, B lymphocyte stimulator; CYC, cyclophosphamide; HDSC, high-dose systemic corticosteroids; LN, lupus nephritis; MMF, mycophenolate mofetil; NPSLE, neuropsychiatric lupus; SLE, systemic lupus erythematosus.

risk of initial flare and lowered the frequency of flares when compared to placebo. This suggests that rituximab might not work well as induction therapy, but rather as an adjunct to control severe SLE manifestations. In a systematic review of EXPLORER with two open-label studies, and 22 cohort studies, rituximab was shown to have positive effects in the treatment of non-renal SLE, ${ }^{38}$ with good effect on disease activity, serology, and corticosteroid-sparing abilities. Similarly, LUNAR did show that patients treated with rituximab had greater improvements in complement levels, anti-double-stranded DNA (dsDNA) levels, and proteinuria than those treated with placebo. $^{36}$

Five cohort studies have assessed the effect of rituximab on neuropsychiatric SLE (NPSLE), ${ }^{31,32,34,39,40}$ reporting a response rate of $73 \%-100 \%$. This includes a case series of 10 patients with severe, refractory NPSLE who all responded to rituximab; ${ }^{32}$ three patients demonstrated 
improvement on magnetic resonance imaging (MRI). However, these studies also noted a high proportion (45-$60 \%$ ) of NPSLE patients treated with, and responding to, rituximab experienced relapse within 17 months of rituximab, despite continuing on maintenance therapy. Thus, it remains difficult to pinpoint a specific role for rituximab in the treatment of NPSLE.

\section{Safety}

Patients in the EXPLORER trial experienced similar numbers of adverse events in the rituximab group $(37.9 \%)$ compared to the placebo group (36.4\%). Most were upper respiratory tract infections and infusion-related adverse events. More patients developed severe sepsis in the placebo group (17\%) than the rituximab group $(9.5 \%)$. Three patients on rituximab therapy died: one with perforated bowel, one from multiple drug intoxication, and one whose cause of death was unknown. Patients in the LUNAR trial experienced similar numbers of adverse events in the rituximab and placebo groups as well, with the most common adverse events again being infection and infusion-related adverse events. Two patients on rituximab therapy died: one due to sepsis and the other due to alveolar hemorrhage 2 months after the first rituximab infusion.

Progressive multifocal leukoencephalopathy (PML) is a rare but well-recognized potential adverse effect of rituximab. None of the patients in EXPLORER or LUNAR developed PML, but two patients on treatment with rituximab in real-world clinical use have been reported to have developed PML. ${ }^{41}$

Due to the chimeric nature of rituximab, its therapy course can be complicated by the development of human anti-chimeric antibodies (HACA). There were three patients in the EXPLORER trial and one in the LUNAR trial with HACAs who also experienced serious adverse events (serum sickness and severe infusion-related reactions). There are also different schedules to administer rituximab therapy, sometimes for convenience of administration, though there do not appear to be differences in tolerability or side effects. $^{31}$

\section{Belimumab}

\section{Clinical Efficacy}

Belimumab is a fully humanized monoclonal antibody against BlyS, and has completed phase III trials in both intravenous and subcutaneous forms (Table 1). Belimumab is FDA-approved for the treatment of seropositive, moderate SLE. In the two international, multi-center, randomized, placebo-controlled phase III clinical trials, $, 9,10$ BLISS-52 and BLISS-76, autoantibody-positive adult patients with active SLE and SLEDAI over 6 were randomized to receive either intravenous infusions of belimu$\mathrm{mab}$ (at $1 \mathrm{mg} / \mathrm{kg} / \mathrm{dose}$ or $10 \mathrm{mg} / \mathrm{kg} /$ dose) or placebo in addition to standard-of-care (SOC) SLE treatment. We have previously reviewed these trials in-depth in other review articles. ${ }^{37,42}$ Both trials achieved their primary endpoints, with a statistically significant improvement in SRI4 over placebo at week 52. Both studies also demonstrated reduced SLE disease activity and severe flares compared to placebo.

Post-hoc analyses from BLISS-52 and BLISS-76 demonstrated that belimumab plus SOC SLE therapy significantly reduced the rate of disease flares, decreased serologic SLE activity, and permitted lower corticosteroid doses when compared to placebo cohort on SOC SLE therapy only. ${ }^{43}$ Belimumab also appeared to improve quality of life in SLE patients. ${ }^{44}$

BLISS-SC investigated the efficacy and safety of subcutaneous injections of belimumab compared to placebo. ${ }^{45}$ BLISS-SC randomized 556 patients with SLE for treatment with belimumab at $200 \mathrm{mg}$ subcutaneously once weekly plus SOC medications, and 280 SLE patients for treatment with placebo plus SOC medications for 52 weeks. The primary endpoint of achievement of SRI-4 response 52 weeks after initiation of belimumab was met by $61.4 \%$ of the patients treated with belimumab, compared to $48.4 \%$ of the patients in the placebo group $(p=0.0006)$. The addition of subcutaneous belimumab to SOC SLE medications also significantly decreased severe disease flare rates compared to placebo $(60.6 \%$ vs $68.6 \%$, respectively, $\mathrm{p}=0.0004)$, and more patients in the belimumab cohort were able to taper their corticosteroid dosages by over $25 \%$ ( $18 \%$ compared to $12 \%$ of the patients given placebo, $\mathrm{p}=\mathrm{NS}$ ).

Most recently, belimumab was FDA-approved to treat seropositive, moderate SLE in children 5-17 years of age in 2019. PLUTO is an ongoing, combined Phase II and III double-blind placebo-controlled, randomized trial of the use of intravenous belimumab at $10 \mathrm{mg} / \mathrm{kg} / \mathrm{dose}$ once every 4 weeks in pediatric SLE. ${ }^{46}$ PLUTO randomized 53 pediatric SLE patients to treatment with belimumab plus SOC medications, and 40 patients to be given placebo plus SOC medications. Although this trial was not designed or powered to have significance, given the relative rarity of pediatric SLE, 53\% of the children with SLE 
treated with belimumab met the primary endpoint of SRI-4 response at 52 weeks, as compared to $44 \%$ of the children given placebo. The use of belimumab allowed $20 \%$ of the patients to taper their corticosteroids over the duration of the trial, though this was comparable to the $21 \%$ of the patients on placebo that also successfully tapered their corticosteroids.

Patients of Black race and/or Hispanic ethnicity can have a more severe disease course, and the EMBRACE trial ${ }^{47}$ was performed to investigate the efficacy and safety of intravenous belimumab in Black SLE patients. EMBRACE is a multi-center, double-blind, placebocontrolled, randomized trial in Black SLE patients over 18 years of age. The primary endpoint was achievement of an SRI-4 response at 52 weeks was met by $49 \%$ of the patients treated with belimumab plus SOC medications, compared to $41.6 \%$ of the patients given placebo plus SOC medications $(\mathrm{p}=\mathrm{NS})$. Numerically more patients were able to taper corticosteroids after starting belimumab, but this number was also not statistically significant.

A subgroup analysis of 267 patients with LN in these trials suggests that belimumab used in combination with MMF may improve nephritis, ${ }^{48}$ leading to the development of the BLISS-LN trial to investigate the usefulness of addition of belimumab to SOC therapy to treat $\mathrm{LN}^{49}$ BLISS-LN randomized 448 adult SLE patients with active, biopsy-proven class III, IV and/or V lupus nephritis 1:1 to receive belimumab or placebo, plus SOC therapy, for 104 weeks. The primary endpoint was defined as a urine protein/creatinine ratio of $<0.7$, estimated glomerular filtration rate within $20 \%$ of the pre-flare value or $>60 \mathrm{~mL} / \mathrm{min} /$ $1.73 \mathrm{~m}^{2}$, and no rescue therapy; this was achieved by significantly more LN patients on belimumab (43\%) than placebo $(32 \%)(\mathrm{p}=0.03)$. SOC induction therapy included high-dose corticosteroids (HDSC) and MMF, or HDSC and CYC. Response in the belimumab cohort was superior to placebo if the induction therapy was HDSC and MMF, but not HDSC and CYC. It is also worth noting that only $30 \%$ of the SLE patients enrolled were of Black race, and that response in the belimumab cohort was superior to placebo in those not of Black race compared to those who identified as Black.

The CALIBRATE trial (combination of antibodies in lupus nephritis: belimumab and rituximab assessment of tolerance and efficacy) investigated the use of rituximab followed by belimumab in adult SLE. Anti-CD20 agents such as rituximab spare the early pre-B and plasma cells, as these B-cell populations do not express CD20 on their surfaces. ${ }^{50}$ Sparing plasma cells in particular allows for the development of long-term memory B cells. In addition, BlyS levels have been shown to rise after B-cell depletion. ${ }^{51}$ Thus, giving belimumab, an agent that targets BlyS, after rituximab may help prevent re-emergence of autoreactive B cells after B-cell depletion. A phase II randomized trial of rituximab plus $\mathrm{CYC}$ followed by belimumab for treatment of lupus nephritis (CALIBRATE) enrolled 43 adults with recurrent or refractory LN (biopsyproven class III or IV LN, alone or in combination with class V LN) who were randomized 1:1 to receive belimumab or placebo infusions after treatment with rituximab and CYC. All patients had been treated with either CYC or MMF in the past; exclusion criteria included those treated with rituximab in the past at any time, or another B-cell biologic within the 12 months before enrollment. The trial's primary endpoint was the safety of the study treatment regimen (defined as having at least one severe infectious adverse event such as pneumonia, sepsis, or cellulitis); prior to week $48,9.5 \%$ of the patients who received belimumab after rituximab and CYC experienced such an infection compared to $23 \%$ of the patients receiving placebo $(\mathrm{p}=\mathrm{NS})$.

Only seven patients who received belimumab and six who received placebo were evaluated at week 96 for efficacy of treatment regimen, with five patients who received belimumab demonstrating complete renal response compared to four patients who received placebo. The other 29 patients were excluded due to leaving the study or meeting a criterion for discontinuation, eg, disease flare or worsening LN during treatment. B-cell depletion was achieved in both cohorts by week 12, and continued to be consistently lower in the cohort receiving belimumab at later time points. Moreover, none of the patients who received belimumab experienced reconstitution of their B cells at week 24, compared with 5 out of 14 patients who received placebo $(\mathrm{p}=0.04)$. Consistent with this observation, 8 of 9 patients in the belimumab cohort had decreased numbers of anti-nuclear antibody (ANA)positive B cells (B cells that express a surface receptor that can bind nuclear antigens) from baseline compared to 5 out of 7 patients in the placebo cohort who demonstrated increased numbers of ANA-positive B cells at week 48 . This supports the theory that belimumab delays reconstitution of ANA-positive B cells. It is worth noting, however, that the authors concluded there was no significant clinical efficacy of adding belimumab after cyclophosphamide and 
rituximab treatment, even though some of the biological effects (described above) occurred as predicted.

There are numerous reports and prospective cohort studies investigating the real-world use of belimumab in addition to SOC therapy for SLE. ${ }^{52-54}$ Rates of efficacy and incidence of adverse events appear to be quite similar to trial data. Currently, clinical trials for the use of belimumab in BLISS-BELIEVE (NCT 03312907), ${ }^{55}$ comparing the use of belimumab plus rituximab to belimumab alone, and subcutaneously in pediatric SLE (NCT 04179032) are underway. ${ }^{56}$

\section{Adverse Effects}

Comparable rates of adverse effects were observed over time in both the intravenous and subcutaneous belimumab trials. ${ }^{9,10,45}$ The phase II continuation of intravenous belimumab study noted that the rates of severe adverse events, including severe infection, were stable or decreased during 7 years of belimumab treatment. ${ }^{57}$ In both trial data and real-world use, the most common adverse effects and reasons for discontinuation of belimumab therapy are infection and lack of response. ${ }^{53,57,59}$

It is worthwhile noting that the phase III trials suggested a two-fold higher likelihood of developing a psychiatric disorder on belimumab therapy if the patient had a history of existing psychiatric disease. Up to $16 \%$ of the patients in the belimumab trials reported a psychiatric event while on treatment with belimumab. ${ }^{58,59}$ Over $50 \%$ of these patients reported experiencing anxiety or insomnia; $0.1-0.4 \%$ of the patients reported suicidal ideation. Moreover, there have been 8 reported cases of PML in adult SLE patients treated with belimumab, ${ }^{60,61}$ with at least two resulting in death.

The mortality rate on belimumab therapy is $0.4 / 100$ patient-years, lower than the mortality rate for SLE patients in general (1.63/100 patient-years). ${ }^{62}$ Malignancies were described in 26 patients while on treatment with belimumab, with a peak incidence of seven to eight patients between 2 and 4 years of initiation of belimumab. There were no additional adverse events noted in the BLISS-LN trial, nor in the CALIBRATE trial. Although all patients in the CALIBRATE trial experienced at least one adverse event, there were no deaths and no opportunistic infections.

There were no additional safety signals noted in the PLUTO trial. ${ }^{46}$ Of note, there was one death in the placebo group and none in the belimumab group. There were no malignancies noted in either group during the trial. Two patients on belimumab reported depression or thoughts of self-harm. Two patients in the placebo cohort developed suicide ideation, compared to none in the belimumab cohort. In our real-world study of belimumab, there were 39 patients whose disease was diagnosed prior to their 19th birthday. ${ }^{37}$ One developed biopsy-proven class IV LN while on belimumab therapy. In addition, three patients developed severe neuropsychiatric side effects while on belimumab, including one with suicidal ideation and attempt and one with new-onset cerebral vasculitis as evidenced on imaging.

\section{Tabalumab}

\section{Clinical Efficacy}

Similar to belimumab, tabalumab is a fully human monoclonal antibody against both soluble and membrane-bound BlyS. ${ }^{11}$ Two phase III randomized, multi-center, doubleblinded, placebo-controlled trials were conducted across all continents - ILLUMINATE-1 and ILLUMINATE-2 (Table 2). ILLUMINATE-1 randomized 1138 adults with non-renal, moderate-to-severe SLE 1:1:1 to receive tabalumab $120 \mathrm{mg}$ subcutaneously once every 2 weeks, tabalumab $120 \mathrm{mg}$ subcutaneously once every 4 weeks, or placebo subcutaneously once every 2 weeks, in addition to SOC SLE treatment, for 52 weeks. ${ }^{63}$ ILLUMINATE-2 randomized 1124 patients with moderate-to-severe SLE in a similar fashion, stratifying for anti-double-stranded DNA antibody status and ancestry. ${ }^{11}$

The primary efficacy endpoint of ILLUMINATE-1 was not met in either tabalumab cohort. However, ILLUMINATE-2 met the primary endpoint of SRI-5 response in the cohort receiving tabalumab $120 \mathrm{mg}$ every 2 weeks, but not the other tabalumab cohort or placebo $(\mathrm{p}=0.002)$. (SRI-5 is similar to SRI-4 response but with a 5 or more point reduction in SLEDAI-2K score.) It is worth noting that ILLUMINATE-2 had similar efficacy to belimumab trials ( $35 \%$ for low dose vs $28 \%$ for placebo in ILLUMINATE-2) and that it met the primary endpoint because of the relatively large numbers enrolled in the trial. Several secondary endpoints were identified, including time to first disease flare and the proportion of patients able to taper corticosteroids. In both ILLUMINATE-1 and ILLUMINATE-2, there was no difference in time to first disease flare in either the tabalumab or placebo cohorts, and no difference in whether corticosteroids were able to be tapered/discontinued. Moreover, post hoc analysis of renal parameters in patients who were part of the intention-to-treat cohort demonstrated that tabalumab did not significantly affect 
Table 2 Newer B-Cell-Targeted Therapies Under Investigation for Treatment of Systemic Lupus Erythematosus

\begin{tabular}{|c|c|c|}
\hline $\begin{array}{l}\text { Name of Medication and Mechanism of } \\
\text { Action }\end{array}$ & $\begin{array}{l}\text { Significant Trial/ } \\
\text { Study }\end{array}$ & Significant Findings \\
\hline $\begin{array}{l}\text { Tabalumab: Human anti-BlyS monoclonal } \\
\text { antibody (subcutaneous) }\end{array}$ & $\begin{array}{l}\text { ILLUMINATE-I } \\
\text { and ILLUMINATE- } \\
2^{11,63}\end{array}$ & $\begin{array}{l}\text { International phase III trials that did not meet primary or secondary } \\
\text { efficacy endpoints. No longer manufactured. }\end{array}$ \\
\hline \multirow[t]{2}{*}{$\begin{array}{l}\text { Atacicept: Recombinant human fusion protein } \\
\text { of TACI binding BlyS and APRIL (subcutaneous) }\end{array}$} & ADDRESS $\|^{65}$ & $\begin{array}{l}\text { Phase Ilb trial that met primary endpoint in patients with SLEDAI over } 10 \\
\text { at baseline, and also decreased flares. }\end{array}$ \\
\hline & APRIL-SLE ${ }^{12}$ & Phase III trial that did not meet primary endpoint. \\
\hline \multirow[t]{2}{*}{$\begin{array}{l}\text { Blisibimod: Peptibody inhibiting BlyS } \\
\text { (subcutaneous) }\end{array}$} & PEARL-SC ${ }^{68}$ & $\begin{array}{l}\text { Phase II trial that met primary endpoint in seropositive patients with } \\
\text { SLEDAI over } 10 \text { at baseline. }\end{array}$ \\
\hline & CHABLIS-SCI ${ }^{13}$ & $\begin{array}{l}\text { Phase III trial that did not meet primary endpoint in sero-positive patients } \\
\text { with SLEDAI over } 10 \text { at baseline; however, may be effective as } \\
\text { corticosteroid-sparing agent and also in treating LN. }\end{array}$ \\
\hline $\begin{array}{l}\text { Ocrelizumab: Human anti- } \\
\text { CD20 monoclonal antibody (intravenous) }\end{array}$ & Phase III trials ${ }^{15,73}$ & $\begin{array}{l}\text { Initial results suggested some efficacy in treating LN inseropositive } \\
\text { patients; however, trial was terminated prematurely secondary to high } \\
\text { rate of serious infections. A second phase III trial was terminated } \\
\text { prematurely due to inefficacy. No longer being investigated in SLE. }\end{array}$ \\
\hline $\begin{array}{l}\text { Obinutuzumab: Human anti-CD20 monoclonal } \\
\text { antibody (intravenous) }\end{array}$ & NOBILITY ${ }^{16}$ & $\begin{array}{l}\text { Phase II trial that did not meet primary endpoint of complete renal } \\
\text { response; however, overall response, including partial renal response, was } \\
\text { significantly higher in treatment cohort. Effective at B-cell depletion in } \\
\text { over } 90 \% \text { of patients. }\end{array}$ \\
\hline $\begin{array}{l}\text { Ofatumumab: Human anti-CD20 monoclonal } \\
\text { antibody (intravenous) }\end{array}$ & Case series $^{17}$ & $\begin{array}{l}\text { Eight of } 16 \mathrm{LN} \text { patients had partial or complete renal remission. B-cell } \\
\text { depletion achieved in 12/16 patients. Useful alternative in rituximab- } \\
\text { allergic patients. }\end{array}$ \\
\hline $\begin{array}{l}\text { Obexelimab: Human anti-CDI9 monoclonal } \\
\text { antibody (intravenous) }\end{array}$ & Phase II trial ${ }^{18}$ & Did not meet primary endpoint. No longer being investigated in SLE. \\
\hline Fenebrutinib: BTK inhibitor (oral) & Phase II trial ${ }^{19}$ & $\begin{array}{l}\text { Did not meet primary endpoint; however, fenebrutinib did significantly } \\
\text { reduce levels of CDI9-positive B cells, including plasmblasts. }\end{array}$ \\
\hline \multirow[t]{2}{*}{$\begin{array}{l}\text { Bortezomib: Proteasome inhibitor (intravenous } \\
\text { or subcutaneous) }\end{array}$} & $\mathrm{RCT}$ trial $^{20}$ & $\begin{array}{l}\text { Conducted in Japan - did not meet primary endpoint. Only one patient } \\
\text { treated with bortezomib had decrease in autoantibodies, compared to } 4 \text { in } \\
\text { placebo cohort. }\end{array}$ \\
\hline & Case series $^{93}$ & $\begin{array}{l}\text { Conducted in Spain - } 10 \text { patients with severe refractory LN achieved } \\
\text { partial renal response, and I complete response. Concern for high } \\
\text { number and severity of SAE in treatment cohorts. May play a role in } \\
\text { salvage therapy (short-term use). }\end{array}$ \\
\hline
\end{tabular}

Abbreviations: APRIL, A proliferation-inducing ligand; BlyS, B lymphocyte stimulator; LN, lupus nephritis; SAE, serious adverse effect; SLEDAl, systemic lupus erythematosus disease activity index; SLE, systemic lupus erythematosus; TACl, transmembrane activator calcium moderator and cyclophilin ligand interactor.

serum creatinine, and urine protein/creatinine level. No difference was seen in the number of renal disease flares over 52 weeks in any cohort. ${ }^{64}$

\section{Adverse Effects}

Both ILLUMINATE-1 and ILLUMINATE-2 had comparable numbers of patients who experienced an adverse effect (approximately $40 \%$ in all cohorts receiving tabalumab), which was also comparable to the placebo cohort. Although both studies noted there were no serious safety signals, ILLUMINATE-2 revealed $8.5 \%$ of the patients on tabalumab had depression and three patients in the tabalumab cohorts attempted suicide while on treatment. There were also three deaths in the placebo and treatment groups in ILLUMINATE2. Tabalumab was discontinued by the manufacturer shortly after the equivocal data from the two phase III trials. 


\section{Atacicept Clinical Efficacy}

Atacicept is a human recombinant fusion protein of the transmembrane activator calcium moderator and cyclophilin ligand interactor (TACI) receptor and $\mathrm{IgG}$, that binds to BlyS and a proliferation-inducing ligand (APRIL). BlyS and APRIL are elevated in sera from SLE patients, suggesting that dual blockade by atacicept may be more effective than blocking BlyS alone. ${ }^{12}$ The phase II $b$ trial (ADDRESS II) was a 24 week, multi-center, randomized, double-blinded, placebo controlled trial (Table 2). ${ }^{65}$ Autoantibody-positive SLE patients with active disease (SLEDAI over 6) were randomized 1:1:1 to receive atacicept $75 \mathrm{mg}(\mathrm{n}=100)$, atacicept $150 \mathrm{mg}(\mathrm{n}=102)$ or placebo $(n=100)$. The primary endpoint of SRI-4 response was not met in any of the atacicept cohorts compared to placebo at week $24(\mathrm{p}=0.12)$; however, analysis of only the cohort with high disease activity (SLEDAI-2K $>10$ ) at baseline did meet the primary endpoint in the SLE patients receiving atacicept $150 \mathrm{mg}$, but not $75 \mathrm{mg}$, compared to placebo $(\mathrm{p}=0.03)$. Moreover, analysis of only the serologically active cohort revealed that these patients met the primary endpoint in all atacicept cohorts compared to placebo ( $\mathrm{p}=0.005$ in both cohorts). Atacicept also decreased the risk of flare, as a secondary endpoint $(\mathrm{p}=0.03)$, at both $75 \mathrm{mg}$ and $150 \mathrm{mg}$ doses in the cohort with serologically active disease. There was no difference in reduction of corticosteroid dosing in either atacicept cohort.

Interestingly, post hoc analyses of ADDRESS II demonstrated that low disease activity (LDA) and Lupus Low Disease Activity State (LLDAS) were achieved at week 24 in the patients with high disease activity receiving atacicept $150 \mathrm{mg}(\mathrm{p}<0.01)$ compared to placebo. ${ }^{66}$ In addition, high baseline levels of both serum BlyS and APRIL correlated with a greater treatment response, and increased atacicept exposure correlated with reduced flare rates. ${ }^{67}$ The greater reduction in levels of immunoglobulin and plasma and naïve B-cell numbers was associated with greater reductions in flare rate, suggesting there is a dose-response relationship between atacicept concentrations and reduced serum levels of B cells and immunoglobulins. This also suggests that measuring baseline levels of BlyS and APRIL may be useful in identifying SLE patients who may benefit the most from atacicept therapy.

The phase III APRIL-SLE randomized, double-blinded, placebo-controlled trial randomized 461 patients 1:1:1 in a similar fashion to ADDRESS II $^{12}$ to be followed over 52 weeks. The primary endpoint was not met in either cohort receiving atacicept, and in fact the atacicept $150 \mathrm{mg}$ arm was discontinued prematurely due to 2 deaths secondary to infection. There was also no difference in the atacicept $75 \mathrm{mg}$ cohort compared to placebo for time to first flare.

\section{Adverse Effects}

The safety profile of atacicept was acceptable in ADDRESS II, with no increase in the overall frequency of serious adverse effects (SAE) or serious infections when compared to placebo. Two deaths related to alveolar hemorrhage from pulmonary infections occurred in the patients receiving atacicept $150 \mathrm{mg}$ in the APRIL-SLE trial. Other infectious SAE in APRIL-SLE include eight patients reporting pneumonia.

\section{Blisibimod \\ Clinical Efficacy}

Blisibimod is a molecule that inhibits BlyS and has features of both a peptide and antibody (peptibody). The phase II placebo-controlled trial of blisibimod in SLE (PEARL-SC) did not meet primary efficacy endpoint of SRI-5 response; however, similar to trials in other B cellactivating and-stimulating factor inhibitors, an improved treatment efficacy was seen in serologically active SLE patients with higher disease activity. ${ }^{68}$ Thus, the phase III trial of blisibimod in SLE (CHABLIS-SC1) enrolled seropositive SLE patients with SLEDAI-2K score of at least 10 (high disease activity). ${ }^{13}$ CHABLIS-SC1 randomized 442 patients to receive blisibimod subcutaneously every week or placebo, in addition to SOC SLE therapy (Table 2). Although the study did not meet its primary endpoint of SRI-6 response at week 52, blisibimod appears to be effective in being corticosteroid-sparing: after 8 weeks on blisibimod, SLE patients were able to reduce their corticosteroid daily doses and keep them low through weeks 24 and 52. More SLE patients treated with blisibimod achieved a sustained corticosteroid taper through week 52 compared with those receiving placebo (17\% compared to $9 \%$, respectively, $\mathrm{p}=0.02$ ). Moreover, significantly more SLE patients with renal disease treated with blisibimod achieved over $50 \%$ reduction in urinary protein/creatinine ratio at week 24 maintained through week 52, when compared to placebo $(\mathrm{p}<0.05)$.

\section{Adverse Effects}

Blisibimod appeared to be well tolerated, with similar numbers of patients experiencing SAEs in the treatment 
arm compared to placebo (13\% compared to $17 \%$, respectively). Only $6 \%$ of the patients treated with blisibimod reported a serious infection, compared to $17 \%$ treated with placebo. There were no deaths in the blisibimod cohort.

\section{Epratuzumab}

\section{Clinical Efficacy}

CD22 is expressed on mature B cells, but not plasma cells or memory B cells, and modulates B-cell activation and migration by acting as an inhibitory co-receptor of the B-cell receptor. Epratuzumab is a humanized anti-CD22 monoclonal antibody that binds to CD22 to transduce a negative signal to inhibit $\mathrm{B}$ cell activation. ${ }^{14}$ Initial epratuzumab phase II/III trials (ALLEVIATE-1 and -2) were discontinued prematurely because of interruption in medication supply. ${ }^{69}$ However, exploratory pooled analyses found that response to epratuzumab at $360 \mathrm{mg} / \mathrm{m}^{2}$ at week 12 were $44 \%$ (15 out of 34 patients) compared to $30 \%$ for placebo ( 9 out of 30 patients). Subsequent phase III trials (EMBODY-1 and EMBODY-2) randomized 786 and 788 patients respectively to receive epratuzumab plus standard-of-care SLE therapy, and 249 and 263 patients respectively to receive placebo plus SOC SLE therapy for 48 weeks (Table 1). ${ }^{14}$ Although rapid improvements from baseline were initially seen in both placebo and epratuzumab cohorts in both studies, neither study achieved their primary efficacy endpoint. Primary efficacy endpoint was defined as improvement at week 48 based on the British Isles Lupus Assessment Group-based Combined Lupus Assessment (BICLA). ${ }^{70}$ In EMBODY-1, $37.5 \%$ of the patients treated weekly with $600 \mathrm{mg}$ epratuzumab achieved primary endpoint, compared to $34.1 \%$ of patients receiving placebo $(\mathrm{p}=\mathrm{NS})$. In EMBODY-2, 35.2\% of the patients treated weekly with $600 \mathrm{mg}$ of epratuzumab achieved primary endpoint, compared to $33.5 \%$ of those receiving placebo $(\mathrm{p}=\mathrm{NS})$.

\section{Adverse Effects}

In all of the phase III trials, there were no serious safety signals. Between $17 \%$ and $19 \%$ of the patients receiving epratuzumab in the EMBODY trials experienced an SAE compared to $18 \%$ of the patients receiving placebo. ${ }^{14}$ Approximately $35 \%$ of the patients receiving epratuzumab in the ALLEVIATE trials experienced an SAE.

\section{Daratumumab Clinical Efficacy}

Daratumumab is a fully humanized monoclonal antibody against CD38, a surface marker found on plasmablasts.
SLE patients appear to express CD38 at a higher level on plasmablasts, CD19+ mature B cells, and plasmacytoid dendritic cells. $^{71}$ Memory $\mathrm{T}$ cells expressing CD38 have a more expansive population in SLE patients compared to healthy adults. It has been used to successfully treat two women with refractory lupus (one with refractory lupus nephritis, the other with autoimmune hemolytic anemia among other clinical manifestations of lupus that were unresponsive to a multitude of immunosuppressive therapies, including bortezomib). However, long-term efficacy will depend on prevention of the formation of autoimmune plasmablasts. Both patients treated with daratumumab received belimumab starting 4 weeks after the last daratumumab infusion, inhibiting the activation and proliferation of $B$ cells.

\section{Newer Anti-CD20-Targeted Therapies}

CD20 is a B-cell surface marker, expressed on B cells from pre-B to memory $B$ cells. It is not expressed by pro-B cells or antibody-producing plasmablasts and plasma cells. Thus, anti-CD20- targeted therapies spare early B cells and plasma B cells; sparing plasma cells allows for retention of long-term immune memory and B-cell reconstitution after depletion.

Due to the maintenance of antibody production by plasma cells, administration of CD20 inhibitors almost completely depletes peripheral B cells, but immunoglobulin levels are not dramatically reduced. ${ }^{72}$ This suggests that the clinical benefit of this type of B-cell depletion therapy may stem from the loss of other prominent B cell functions such as antigen presentation, production of inflammatory cytokines, activation of T cells, and creation of ectopic lymphoid follicles.

Newer generations of humanized CD20-targeted therapies, such as ocrelizumab, obinutuzumab, and ofatumumab, have been developed in recent years to address the issue of rituximab immunogenicity. However, their use could lead patients to develop human anti-human antibodies (HAHAs). To boost efficacy, many of the secondgeneration anti-CD20 monoclonal antibodies have increased binding affinity to the $\mathrm{Fc}$ receptor on $\mathrm{B}$ cells and increased CDC and/or ADCC. These agents may be particularly useful in SLE patients who have demonstrated a response to rituximab in the past, but are unable to receive further doses of rituximab due to a developed rituximab allergy. 


\section{Ocrelizumab}

Ocrelizumab is a fully humanized monoclonal antibody against CD20, with higher ADCC activity and lower CDC effects compared to rituximab in SLE patients. ${ }^{73}$ The phase III randomized, double-blinded, placebo-controlled trial randomized 762 patients with seropositive SLE and active, biopsy-proven class III or IV lupus nephritis, either alone or in combination with class $\mathrm{V}$ disease, 1:1:1 to receive treatment with intravenous ocrelizumab at $400 \mathrm{mg}$ or $1000 \mathrm{mg}$, or placebo, in addition to SOC SLE therapy for 48 weeks. ${ }^{15}$ Ocrelizumab, at either dose, or placebo was given on days 1 and 15 , followed by a single infusion at week 16 and every 16 weeks thereafter, up to 48 weeks. Although initial results suggested ocrelizumab may have some efficacy in treating lupus nephritis, this trial was terminated prematurely due to a high rate of serious infections in the cohort treated with ocrelizumab when compared to placebo (up to $36 \%$ of the patients treated with ocrelizumab $400 \mathrm{mg}$ compared to $27 \%$ of those treated with placebo). Serious infections that were reported in patients on ocrelizumab treatment (both cohorts) include pneumonia (8\%) and cellulitis. Five patients treated with ocrelizumab reported opportunistic infections, including Pneumocystis jirovecii and cytomegalovirus pneumonia, disseminated herpes zoster, systemic herpes, and cryptococcal meningitis. Moreover, neutropenia as an SAE was reported only in patients on ocrelizumab treatment and there were eight deaths in the ocrelizumab cohorts. This imbalance appeared to occur more often in patients treated with MMF as background standard of care therapy and not in those treated with background CYC.

A second phase III trial to determine the optimal dosing of ocrelizumab in treating SLE was also terminated early due to the perception that ocrelizumab would have no added benefit in treating SLE (NCT00539838). ${ }^{74}$ Of interest, ocrelizumab was shown to have great efficacy in treating multiple sclerosis in several phase III trials. ${ }^{75,76}$

\section{Obinutuzumab}

Obinutuzumab, a fully humanized anti-CD20 monoclonal antibody, has been shown to be at least twice as effective as rituximab at B-cell depletion, inducing cytotoxicity of CD20-positive B cells, and activating ADCC activity in natural killer (NK) cells and neutrophils. ${ }^{77} \mathrm{~B}$ cells from SLE patients also internalize rituximab more quickly than obinutuzumab. NOBILITY is a 104-week phase II randomized, double-blind, controlled trial studying safety and efficacy of obinutuzumab plus MMF in lupus nephritis. ${ }^{16}$
NOBILITY randomized 125 SLE patients with active, biopsy-proven class III or IV lupus nephritis to receive obinutuzumab $1000 \mathrm{mg}$ or placebo intravenously, in addition to MMF and corticosteroids. Preliminary results show that the primary outcome, complete renal response at week 52, was not met; however, overall response, including complete and partial renal responses, was met by $35 \%$ of the patients treated with obinutuzumab compared to $22 \%$ of the patients receiving placebo $(\mathrm{p}=0.02)$. Over $90 \%$ of the patients treated with obinutuzumab had no detectable peripheral B cells at day 28. Moreover, there were no increased rates of SAE or serious infections in the obinutuzumab cohort when compared with placebo. There were no deaths in patients receiving obinutuzumab through week 52.

\section{Ofatumumab}

Ofatumumab is a fully humanized anti-CD20 monoclonal antibody that has been approved to treat chronic lymphocytic leukemia, autoimmune hemolytic anemia and immunemediated thrombocytopenia. ${ }^{78}$ To date, several case series describe its use in SLE. ${ }^{17,79,80}$ The largest single-center retrospective case series of 16 patients treated with ofatumumab showed that 11 of 16 patients were given ofatumumab for active, refractory, biopsy-proven class III or IV LN, either alone or in combination with class $\mathrm{V}$ disease, and 3 out of 16 patients were given ofatumumab for active, refractory, biopsy-proven class V LN. ${ }^{17}$ All patients had been treated with several immunosuppressive medications including rituximab, CYC, azathioprine, MMF, and corticosteroids; all patients, except one, were maintained on MMF, with or without hydroxychloroquine, and with or without corticosteroids. Overall, eight of the 16 patients $(50 \%)$ responded to ofatumumab treatment with partial or complete response/remission. B-cell depletion was achieved in 12 patients, with comparable time to reconstitution as rituximab seen by the same group. Serological markers of disease including complement levels and autoantibody levels improved after ofatumumab treatment. Five patients reported serious infections; there were no deaths at least 28 months after ofatumumab treatment.

Four patients with active, refractory LN, who initially demonstrated beneficial response to rituximab, were treated with ofatumumab in Sweden. ${ }^{79}$ After treatment, all patients experienced decreased proteinuria and anti-dsDNA antibody levels. One patient with SLE on rituximab received three infusions of ofatumumab after becoming allergic to rituximab. ${ }^{80}$ After treatment, this patient had decreased 
SLEDAI score and normalization of anti-dsDNA antibodies and C3. To date, there are no active clinical trials investigating the safety and efficacy of ofatumumab in SLE.

\section{Anti-CD I 9-Targeted Therapy - Obexelimab}

CD19 is a cell surface marker that is expressed on all B cells, including plasmablasts and a fraction of plasma cells. ${ }^{70}$ Thus, targeting CD19 could provide a more comprehensive depletion of B cells and plasma cells in patients with SLE. Obexelimab (XmAb5871) is a humanized anti-CD19 monoclonal antibody engineered for increased affinity to FcgRIIb, that is a reversible B-cell inhibitor. Co-ligation of CD19 with FcgRIIb inhibits B cells important in pathogenesis of disease.

A Phase II, double-blinded, randomized, placebocontrolled trial was conducted in 104 patients with moderately active SLE. ${ }^{18}$ All patients were given up to $160 \mathrm{mg}$ of intramuscular Depo-Medrol to ameliorate existing manifestations. Improvement of at least 4 points in SLEDAI score, or more than 1 grade decrease in one or more BILAG A or B scores, was required prior to randomization. At randomization, patients were on treatment with only hydroxychloroquine and/or up to $10 \mathrm{mg}$ /day corticosteroids. Primary endpoint was the proportion of patients with no loss of improvement by day 225 in the obexelimab cohort, and was not met $(\mathrm{p}=\mathrm{NS})$. These results did not change with subpopulation analyses of those with seropositive disease. Due to this study not meeting its primary endpoint, the manufacturer of obexelimab decided not to proceed with a phase III trial in SLE, and instead, obexelimab is currently being evaluated for the treatment of IgG4-related disease (NCT02725476). ${ }^{81}$

\section{B-Cell Signaling-Targeted Therapies Bruton's Tyrosine Kinase-Targeted Therapies}

Another area of current investigation is B-cell signaling for targeted therapies to treat SLE. One such target are the tyrosine kinases: Bruton's tyrosine kinase (BTK) is an essential intracellular signaling molecule in the development, survival and activation of B cells. ${ }^{82}$ It is thought that BTK is involved in antigen presentation, B-cell differentiation and production of autoantibodies through B-cell receptor signaling in SLE. ${ }^{83}$ In murine models, BTK inhibition was shown to ameliorate renal, skin, and brain disease in systemic lupus erythematosus. ${ }^{84}$
Fenebrutinib (GDC-0853) is an oral, non-covalent, and highly selective inhibitor of BTK. A phase II trial randomized, placebo-controlled trial evaluated its efficacy and safety in moderate-to-severe SLE. ${ }^{19}$ There were 260 SLE patients randomized 1:1:1 to receive either fenebrutinib $150 \mathrm{mg}$ daily or $200 \mathrm{mg}$ twice daily, or placebo, in addition to SOC SLE therapy, for 48 weeks. Although the primary efficacy endpoint of SRI-4 response was not met, this trial did demonstrate that both doses of fenebrutinib did significantly reduce levels of CD19-positive B cells, antidouble-stranded DNA autoantibodies, immunoglobulins, and a BTK-dependent RNA signature expressed in plasmablasts compared to placebo.

Ibrutinib is an irreversible tyrosine kinase selective inhibitor currently used to treat B-cell malignancies, with a good safety profile. ${ }^{85}$ It binds to BTK causing B-cell apoptosis. In preclinical mouse models of $\mathrm{LN}$, treatment with ibrutinib resulted in reduced levels of autoantibodies and less severe nephritis. ${ }^{86}$ Several other BTK inhibitors are currently in Phase I trials to treat mild to moderate SLE (NCT02537028, NCT03878303). ${ }^{87,88}$

\section{Proteasome Inhibitors}

Another approach to targeting the CD20-negative cells, such as short- and long-lived plasma B cells, that are likely the source of therapy failures with anti-CD20 agents, is to inhibit the proteasome. Proteasomes handle misfolded proteins and are the major non-lysosomal degradation system for proteins produced at high levels during immunoglobulin assembly. Proteasome inhibition causes accumulation of defective immunoglobulin chains, resulting in stress on the endoplasmic reticulum, misfolding of proteins, and subsequent apoptosis of plasma cells. ${ }^{89,90}$ Proteasomes have proven to be critical for plasma cell function due to the plasma cell's high rate of antibody synthesis. Inhibiting the function of the proteasome leads to plasma cell apoptosis, which thus leads to decrease in antibody production that can contribute to disease severity and damage in SLE. ${ }^{90}$

Bortezomib is a proteasome inhibitor that is approved for treatment of multiple myeloma. In lupus-prone MPL/lpr mice, administration of bortezomib was found to be effective in preventing and more importantly treating established SLE. ${ }^{91}$ Other proteasome inhibitors, carfilzomib and delanzomib, showed similar effects in preclinical lupus. ${ }^{92,93}$

A multi-center, double-blinded, randomized controlled trial was conducted on the efficacy and safety of bortezomib in SLE patients in Japan. ${ }^{20}$ Fourteen seropositive SLE patients with moderate disease (SLEDAI of 6 or more 
points), on prednisone for at least 6 months whose dose could not be tapered below 10mg daily, were randomized 1:1 to receive bortezomib or placebo, in addition to SOC SLE therapy, for 24 weeks. The primary endpoint of the change and rate of change in anti-dsDNA antibodies in these patients was not met, nor was a secondary endpoint of the SRI-4, indicating that bortezomib may not be effective for SLE. Only one patient treated with bortezomib had a decrease in anti-dsDNA antibody level, compared with four patients in the placebo cohort. There were no flares at week 24 in the bortezomib cohort.

In Spain, 12 SLE patients were given bortezomib and dexamethasone for the treatment of severe refractory LN. ${ }^{94}$ All immunosuppressive medications were stopped prior to study enrollment, and all patients received cyclophosphamide and corticosteroids, and were re-biopsied before bortezomib. Bortezomib was discontinued at 6 months if there was no improvement in renal function. One patient treated with bortezomib achieved a complete renal response, and 10 patients achieved a partial response, including significant reduction in proteinuria. Decreased levels of anti-dsDNA antibodies, proteinuria, and improvement in $\mathrm{C} 3$ levels were observed.

In Germany, 12 SLE patients received bortezomib, all of whom showed significant clinical improvement based on decrease of SLEDAI by a median of 10 points. ${ }^{95}$ This included a significant reduction in proteinuria in the patients with renal disease. Four patients received bortezomib without dexamethasone; their SLEDAI also markedly decreased by a median of 5 points post-bortezomib. In addition to successful plasma cell depletion, bortezomib was found to reduce type I interferon activity in SLE.

\section{Adverse Effects}

Of concern are the high number and severity of SAEs in SLE patients treated with bortezomib, with at least one patient in the above-mentioned trials developing thrombocytopenic purpura. Almost all patients treated with bortezomib developed fever and localized reactions at the site(s) of administration. Hypogammaglobulinemia was seen in five patients in the Spanish study; two patients had hypogammaglobulinemia persist beyond the end of the study. ${ }^{94}$ Two patients developed sensory neuropathy, leading to bortezomib discontinuation. Polyneuropathy was also seen in the German study. ${ }^{95}$ Overall, 7 of the 12 patients treated with bortezomib discontinued therapy secondary to an adverse event.

The clinical efficacy of bortezomib in several studies is quite remarkable, particularly since all patients had been refractory to prior immunosuppression. Given the high rate of SAE in use of bortezomib to treat SLE, proteasome inhibition may best serve as salvage therapy for refractory SLE patients and not long-term use in maintenance therapy.

\section{Conclusion}

As SLE is a highly heterogeneous disease, personalized targeted therapy is necessary since it is difficult to achieve similar therapeutic effects. Although has been significant progress in SLE treatment over the past decade, there remains considerable morbidity with conventional immunosuppression. B-cell-targeted therapies show great promise in playing a role in SLE therapy; belimumab was approved by the FDA in 2011 for the treatment of seropositive, moderate SLE in adults, and then in 2019 for treatment of seropositive, moderate SLE in patients ages 5-17 years. However, many of the current therapies such as antiCD20 and anti-CD19 agents discussed in this review, have not yielded the expected results or success to treat SLE. In addition, few, if any, of the B-cell-targeted therapies have been investigated in the use of severe SLE, such as severe lupus nephritis or severe and active neuropsychiatric lupus. Moreover, although the phase III trial EXPLORER did not meet primary efficacy endpoint on the use of rituximab in SLE, it did reduce the risk for flare, suggesting that rituximab might play an adjunctive role in controlling severe SLE manifestations and not as induction therapy. BLISSLN demonstrates some promise for use of belimumab in SLE patients with active LN. Currently, it remains difficult to pinpoint a role for B-cell-targeted therapy in treatment of NPSLE, given that several of the B-cell therapies available for treatment of SLE have reported NPSLE-like symptoms or conditions as adverse events. Several new approaches targeting the BAFF-APRIL pathway, B-cell signaling through tyrosine kinases and proteasome inhibitors, and PEGylated anti-CD40 ligand (eg, dapirolizumab) offer new hope in management of SLE. ${ }^{19,88,89,96}$

There remain several unmet needs for targeted therapy in SLE. Emerging targeted B-cell therapies include targeting of the intracellular signaling through BTK and proteasome inhibitors. Because of the complexity of SLE pathogenesis, a medication targeting more than one pathway could be of great therapeutic potential. For example, BTK is expressed on several immune cell types, though functionally it is essential in B cell activation, differentiation, and survival. BTK signaling blockade could therefore impact not only B cells but other 
innate immunity consequences through molecules like Tolllike receptors, and may promote central tolerance. ${ }^{70,97}$

It is disappointing that several targeted therapies did not perform as expected in large phase III trials, or resulted in high rates of SAE; in particular, the newer generation antiCD20, not including ofatumumab, and anti-CD19 monoclonal antibodies do not appear to have a future role in SLE treatment. Other targeted therapies such as ofatumumab and BTK inhibitors do show potential in treatment of SLE, and provide options for patients who may respond to rituximab but develop an allergic reaction. Certainly, the more expensive monoclonal antibody therapies will become more affordable with the advent of biosimilars such as Truxima and Ruxience (rituximab biosimilars), as the ACR recognizes their equivalent efficacy as compared to the original drug in treatment of disease. ${ }^{98}$ Most importantly, advances in understanding complex B-cell function, response to B-cell therapies in SLE, and treatment failures will help us to redesign some of the current B-cell-targeted therapeutics, with hopes of improved efficacy, in the future.

\section{Abbreviations}

ADCC, antibody-dependent cell-mediated cytotoxicity; ADP, antibody-dependent phagocytosis; ANA, anti-nuclear antibody; APRIL, A proliferation-inducing ligand; BILAG, British Isles Lupus Assessment Group; BlyS/BAFF, B lymphocyte stimulator/B-cell-activating factor; BTK, Bruton's tyrosine kinase; CDC, complement-mediated cytotoxicity; dsDNA, double-stranded DNA; FDA, Food and Drug Administration; HACA, human anti-chimeric antibodies; HAHA, human anti-human antibodies; LDA, low disease activity; LLDAS, lupus low disease activity state; LN, lupus nephritis; MRI, magnetic resonance imaging; NPSLE, neuropsychiatric SLE; PGA, physician global assessment; PML, progressive multifocal leukoencephalopathy; SAE, serious adverse effect; SLE, systemic lupus erythematosus; SLEDAI-2K, SLE disease activity index 2000; SOC, standard-of-care; SRI, SLE responder index; TACI, transmembrane activator calcium moderator and cyclophilin ligand interactor; TNF, tumor necrosis factor.

\section{Acknowledgments}

The authors thank Dr B Anne Eberhard for her critical comments.

\section{Funding}

No specific funding was received to carry out the work described in this manuscript.

\section{Disclosure}

The authors declare they have no conflicts of interest, financial or otherwise.

\section{References}

1. Costenbader KH, Feskanich D, Stampfer MJ, et al. Reproductive and menopausal factors and risk of systemic lupus erythematosus in women. Arthritis Rheum. 2007;56:1251-1262. doi:10.1002/art.22510

2. Choi J, Kim ST, Craft J. The pathogenesis of systemic lupus erythematosus - an update. Curr Opin Immunol. 2012;24:651-657. doi:10.1016/j.coi.2012.10.004

3. D'Cruz DP, Khamashta MA, Hughes GR. Systemic lupus erythematosus. Lancet. 2007;369:587-596. doi:10.1016/S0140-6736(07)60279-7

4. Rahman A, Isenberg DA. Systemic lupus erythematosus. $N$ Engl J Med. 2008;358:929-939. doi:10.1056/NEJMra071297

5. Askanase AD, Wallace DJ, Weisman MH, et al. Use of pharmacogenetics, enzymatic phenotyping and metabolite monitoring to guide treatment with azathioprine in patients with systemic lupus erythematosus. J Rheumatol. 2009;36:89-95. doi:10.3899/jrheum.070968

6. Carneiro JR, Sato EI. Double blind, randomized, placebo-controlled clinical trial of methotrexate in systemic lupus erythematosus. J Rheumatol. 1999;26:1275-1279.

7. Nashi E, Wang Y, Diamond B. The role of B cells in lupus pathogenesis. J Biochem Cell Biol. 2010;42:543-550. doi:10.1016/j. biocel.2009.10.011

8. Hahn BH. Belimumab for systemic lupus erythematosus. $N$ Engl $J$ Med. 2013;368:1528-1535. doi:10.1056/NEJMct1207259

9. Navarra S, Guzman RM, Gallacher AE, et al. Efficacy and safety of belimumab in patients with active systemic lupus erythematosus: a randomized, placebo-controlled, Phase 3 trial. Lancet. 2011;377:721-731. doi:10.1016/S0140-6736(10)61354-2

10. Furie R, Petri M, Zamani O, et al. A Phase III, randomized, placebo-controlled study of belimumab, a monoclonal antibody that inhibits B lymphocyte stimulator, in patients with systemic lupus erythematosus. Arthritis Rheum. 2011;63:3918-3930. doi:10.1002/ art.30613

11. Merrill JT, van Vollenhoven RF, Buyon JF, et al. Efficacy and safety of subcutaneous tabalumab, a monoclonal antibody to B-cell activating factor, in patients with systemic lupus erythematosus: results from ILLUMINATE-2, a 52-week, phase III, multicenter, randomized, double blind, placebo-controlled study. Ann Rheum Dis. 2016;75:332-340. doi:10.1136/annrheumdis-2015-207654

12. Isenberg DA, Gordon C, Licu D, et al. Efficacy and safety of atacicept for prevention of flares in patients with moderate-tosevere systemic lupus erythematosus: 52-week data (APRIL-SLE randomized trial). Ann Rheum Dis. 2015;74:2006-2015. doi:10.1136/annrheumdis-2013-205067

13. Merrill JT, Shanahan WR, Scheinberg M, et al. Phase III trial results with blisibimod, a selective inhibitor of B-cell activating factor, in subjects with systemic lupus erythematosus: results from a randomized, double blind, placebo-controlled trial. Ann Rheum Dis. 2018;77:883-889. doi:10.1136/annrheumdis-2018-213032

14. Clowse MEB, Wallace DJ, Furie RA, et al. Efficacy and safety of epratuzumab in moderately to severely active systemic lupus erythematosus. Arthritis Rheumatol. 2017;69:362-375. doi:10.1002/ art.39856

15. Mysler EF, Spindler AJ, Guzman R, et al. Efficacy and safety of ocrelizumab in active proliferative lupus nephritis. Arthritis Rheum. 2013;65:2368-2379. doi:10.1002/art.38037

16. Furie RA, Aroca G, Alvarez A, et al. A phase II randomized, double blind, placebo-controlled study to evaluate the efficacy and safety of obinutuzumab or placebo in combination with mycophenolate mofetil in patients with active class III or IV lupus nephritis (abstract). Arthritis Rheumatol. 2019;71:1125-1134. 
17. Masoud S, McAdoo SP, Bedi R, et al. Ofatumumab for B cell depletion in patients with systemic lupus erythematosus who are allergic to rituximab. Rheumatol. 2018;57:1156-1161. doi:10.1093/rheumatology/key042

18. Merrill JT, June J, Koumpouras F, et al. Top-line results of a Phase 2, double blind, randomized, placebo-controlled study of a reversible B cell inhibitor, XmAb5871, in systemic lupus erythematosus (abstract). Arthritis Rheumatol. 2018;70:266-276.

19. Isenberg DA, Furie RA, Jones N, et al. Efficacy, safety, and pharmacodynamics effects of the Bruton's tyrosine kinase inhibitor, fenebrutinib (GDC-0853), in moderate to severe systemic lupus erythematosus: results of a phase 2 randomized controlled trial (abstract). Arthritis Rheumatol. 2019;71.

20. Ishii T, Tanaka Y, Kawakami A, et al. Multicenter double blind randomized controlled trial to evaluate the effectiveness and safety of bortezomib as a treatment for refractory systemic lupus erythematosus. Mod Rheumatol. 2018;28:986-992. doi:10.1080/ 14397595.2018.1432331

21. Vincent FB, Morand EF, Schneider R, et al. The BAFF/APRIL system in SLE pathogenesis. Nat Rev Rheumatol. 2014;10:365-373. doi:10.1038/nrrheum.2014.33

22. Ritterhouse LL, Crowe ST, Niewold TB, et al. B lymphocyte stimulator levels in systemic lupus erythematosus: higher circulating levels in African American patients and increased production after influenza vaccination in patients with low baseline levels. Arthritis Rheum. 2011;63:3931-3941. doi:10.1002/art.30598

23. Petri M, Stohl W, Chatham W, et al. Association of plasma B lymphocyte stimulator levels and disease activity in systemic lupus erythematosus. Arthritis Rheum. 2008;58:2453-2459. doi:10.1002/art.23678

24. Alexander T, Cheng Q, Klotsche J, et al. Proteasome inhibition with bortezomib induces a therapeutically relevant depletion of plasma cells in SLE but does not target their precursors. Eur J Immunol. 2018;48:1573-1579. doi:10.1002/eji.201847492

25. Isenberg DA, Rahman A, Allen E, et al. BILAG 2004. Development and initial validation of an updated version of the British Isles lupus assessment group's disease activity index for patients with systemic lupus erythematosus. Rheumatol. 2005;44:902-906. doi:10.1093/ rheumatology/keh624

26. Galarza C, Valencia D, Tobon GJ, et al. Should rituximab be considered as the first-choice treatment for severe autoimmune rheumatic diseases? Clin Rev Allergy Immunol. 2008;34:124-128. doi:10.1007/ s12016-007-8028-z

27. Jonsdottir T, Gunnarsson I, Risselada A, et al. Treatment of refractor SLE with rituximab plus cyclophosphamide: clinical effects, serological changes and predictors of response. Ann Rheum Dis. 2007;67:330-334. doi:10.1136/ard.2007.079095

28. Lindholm C, Borjesson-Asp K, Zendjanchi K, et al. Long term clinical and immunological effects of anti-CD20 treatment in patients with refractory systemic lupus erythematosus. J Rheumatol. 2008;35:826-833.

29. Albert D, Dunham J, Khan S, et al. Varibility in the biological response to anti-CD20 B cell depletion in systemic lupus erythematosus. Ann Rheum Dis. 2008;67:1724-1731. doi:10.1136/ ard.2007.083162

30. Kamburova EG, Koenen HJPM, Boon L, et al. In vitro effects of rituximab on the proliferation, activation and differentiation of human B cells. Am J Transplant. 2012;12:341-350. doi:10.1111/j.16006143.2011.03833.x

31. Narvaez J, Rios-Rodriguez V, de la Fuente D, et al. Rituximab therapy in refractory neuropsychiatric lupus: current clinical evidence. Semin Arthritis Rheum. 2011;41:364-372. doi:10.1016/j. semarthrit.2011.06.004

32. Tokunaga M, Saito K, Kawabata D, et al. Efficacy of rituximab (anti-CD20) for refractory systemic lupus erythematosus involving the central nervous system. Ann Rheum Dis. 2007;66:470-475. doi:10.1136/ard.2006.057885
33. Moroni G, Raffiotta F, Trezzi B, et al. Rituximab vs mycophenolate vs cyclophosphamide for induction therapy of active lupus nephritis: a clinical observational study. Rheumatol. 2014;53:1570-1577. doi:10.1093/rheumatology/ket462

34. Ramos-Casals M, Soto MJ, Cuadrado MJ, et al. Rituximab in systemic lupus erythematosus: a systematic review of off-label use in 188 cases. Lupus. 2009;18:767-776. doi:10.1177/0961203309106174

35. Merrill JT, Neuwelt CM, Wallace DJ, et al. Efficacy and safety of rituximab in moderately-to-severely active systemic lupus erythematosus: the randomized, double-blind, phase II/III systemic lupus erythematosus evaluation of rituximab trial (EXPLORER). Arthritis Rheum. 2010;62:222-233. doi:10.1002/art.27233

36. Rovin B, Furie R, Latinis K, et al. Efficacy and safety of rituximab in patients with active proliferative lupus nephritis: the lupus nephritis assessment with rituximab study (LUNAR). Arthritis Rheum. 2012;64:1215-1226. doi:10.1002/art.34359

37. Hui-Yuen JS, Nguyen SC, Askanase AD. Targeted B cell therapies in the treatment of adult systemic lupus erythematosus. Lupus. 2016;25:1086-1096. doi:10.1177/0961203316652491

38. Coco-Ibanez T, Loza-Santamaria E, Peg-Reigosa JM, et al. Efficacy and safety of rituximab in the treatment of non-renal systemic lupus erythematosus: a systematic review. Semin Arthritis Rheum. 2014;44:175-185. doi:10.1016/j.semarthrit.2014.04.002

39. Fernandez-Nebro A, de la Fuente J, Carreno L, et al. Multicenter longitudinal study of B lymphocyte depletion in refractory systemic lupus erythematosus: the LESIMAB study. Lupus. 2012;21:1063-1076. doi:10.1177/0961203312446627

40. Pinto LF, Velasquez CJ, Prieto C, et al. Rituximab induces a rapid and sustained remission in Colombian patients with severe and refractory systemic lupus erythematosus. Lupus. 2011;20:1219-1226. doi:10.1177/0961203311409273

41. Henegar CE, Eudy AM, Kharat V, et al. Progressive multifocal leukoencephalopathy in patients with systemic lupus erythematosus: a systematic literature review. Lupus. 2016;25:617-626. doi:10.1177/ 0961203315622819

42. Guzman M, Hui-Yuen JS. Management of pediatric systemic lupus erythematosus: focus on belimumab. Drug Design Dev Ther. 2020;14:2503-2513. doi:10.2147/DDDT.S216193

43. Van Vollenhoven RF, Petri MA, Cervera R, et al. Belimumab in the treatment of systemic lupus erythematosus: high disease activity predictors of response. Ann Rheum Dis. 2012;71:1343-1349. doi:10.1136/annrheumdis-2011-200937

44. Strand V, Levy RA, Cervera R, et al. Improvements in health-related quality of life with belimumab, a B lymphocyte stimulator-specific inhibitor, in patients with autoantibody-positive systemic lupus erythematosus from the randomized controlled BLISS trials. Ann Rheum Dis. 2014;73:838-844. doi:10.1136/annrheumdis-2012-202865

45. Stohl W, Schwarting A, Okada M, et al. Efficacy and safety of subcutaneous belimumab in systemic lupus erythematosus: a 52-week randomized, double blind, placebo controlled study. Arthritis Rheumatol. 2017;69:1016-1027. doi:10.1002/art.40049

46. Brunner HI, Abud-Mendoza C, Viola DO, et al. Safety and efficacy of intravenous belimumab in children with systemic lupus erythematosus: results from a randomized, placebo-controlled trial. Ann Rheum Dis. 2020;79:1340-1348. doi:10.1136/annrheumdis-2020-217101

47. D'Cruz D, Maksimowicz-McKinnon K, Oates J, et al. Efficacy and safety of belimumab in patients of black race with systemic lupus erythematosus: results from the EMBRACE study. Lupus Sci Med. 2019;6.

48. Dooley A, Houssiau F, Aranow C, et al. Effect of belimumab treatment on renal outcomes: results from the phase III belimumab clinical trials in patients with SLE. Lupus. 2013;22:63-72. doi:10.1177/ 0961203312465781

49. Furie RA, Rovin BH, Joussai F, et al. Two-year, randomized controlled trial of belimumab in lupus nephritis. $N$ Engl J Med. 2020;383:1117-1128. doi:10.1056/NEJMoa2001180 
50. Atisha F, Malkiel S, Harris KM, et al. CALIBRATE: a phase II randomized trial of rituximab plus cyclophosphamide followed by belimumab for the treatment of lupus nephritis. Arthritis Rheumatol. 2020. doi:10.1002/art.41466.

51. Ehrenstein MR, Wing C. The BAFFling effects of rituximab in lupus: danger ahead? Nat Rev Rheumatol. 2016;12:367-372. doi:10.1038/ nrrheum. 2016.18

52. Collins CE, Dall'Era M, Kan H, et al. Response to belimumab among patients with systemic lupus erythematosus in clinical practice settings: 24 month results from the OBSErve study in the USA. Lupus Sci Med. 2016;3:e00118. doi:10.1136/lupus-2015-000118

53. Wallace DJ, Ginzler EM, Merrill JT, et al. Safety and efficacy of belimumab plus standard-of-care therapy for up to 13 years in patients with systemic lupus erythematosus. Arthritis Rheum. 2019;71:1125-1134. doi:10.1002/art.40861

54. Hui-Yuen JS, Reddy A, Taylor J, et al. Safety and efficacy of belimumab to treat systemic lupus erythematosus in academic clinical practices. J Rheumatol. 2015;42:2288-2295. doi:10.3899/jrheum.150470

55. A study to evaluate the efficacy and safety of belimumab administered in combination with rituximab to adult subjects with systemic lupus erythematosus (SLE) - BLISS-BELIEVE. Clinicaltrials.gov identifier: NCT 03312907, accessed 30 August 2020. 2020.

56. A study of subcutaneous (sc) belimumab in pediatric participants with systemic lupus erythematosus (SLE). Clinicaltrials.gov identifier: NCT 04179032, accessed 30 August 2020. 2020.

57. Ginzler EM, Wallace DJ, Merrill JT, et al. Disease control and safety of belimumab plus standard therapy over 7 years in patients with systemic lupus erythematosus. $J$ Rheumatol. 2014;41:300-309. doi: $10.3899 /$ jrheum. 121368

58. Wallace DJ, Navarra SV, Petri MA, et al. Safety profile of belimumab: pooled data from placebo-controlled phase II and III studies in patients with systemic lupus erythematosus. Lupus. 2013;22:144-154. doi:10.1177/0961203312469259

59. Bruce IN, Urowitz M, van Vollenhoven R, et al. Long-term organ damage accrual and safety in patients with SLE treated with belimumab plus standard of care. Lupus. 2016;25:699-709. doi:10.1177/ 0961203315625119

60. Leblanc-Trudeau C, Masetto A, Bocti C. Progressive multifocal encephalopathy associated with belimumab in a patient with systemic lupus erythematosus. J Rheumatol. 2015;42:551-552. doi:10.3899/ jrheum. 140577

61. Raisch DW, Rafi JA, Chen C, et al. Detection of cases of progressive multifocal leukoencephalopathy associated with new biologicals and targeted cancer therapies from the FDA's adverse reporting system. Expert Opin Drug Saf. 2016;15:1003-1011. doi:10.1080/ 14740338.2016.1198775

62. Bernatksy S, BOivin JF, Joseph L, et al. Mortality in systemic lupus erythematosus. Arthritis Rheum. 2006;54:2550-2557. doi:10.1002 art. 21955

63. Isenberg DA, Petri M, Kalunian K, et al. Efficacy and safety of subcutaneous tabalumab in patients with systemic lupus erythematosus: results from ILLUMINATE-1, a 52 week, phase III, multicenter, randomized, double blind, placebo-controlled study. Ann Rheum Dis. 2016;75:323-331. doi:10.1136/annrheumdis-2015-207653

64. Rovin B, Dooley MA, Radhakrishnan J, et al. The impact of tabalumab on the kidney in systemic lupus erythematosus: results from two phase III randomized, clinical trials. Lupus. 2016;25:1597-1601. doi: $10.1177 / 0961203316650734$

65. Merrill JT, Wallace DJ, Wax S, et al. Efficacy and safety of atacicept in patients with systemic lupus erythematosus: results of a 24 week, multicenter, randomized, double blind, placebo-controlled, parallel-arm, phase IIb study. Arthritis Rheumatol. 2018;70:266-276. doi:10.1002/art.40360

66. Morand E, Isenberg DA, Wallace DJ, et al. Attainment of treat-to-target endpoints in SLE patients with high disease activity in the atacicept phase IIb ADDRESS II study. Rheumatol. 2020;59:2930-2938. doi:10.1093/rheumatology/keaa029.
67. Gordon C, Wofsy D, Wax S, et al. Post hoc analysis of the phase II/III APRIL-SLE study: association between response to atacicept and serum biomarkers including BLyS and APRIL. Arthritis Rheumatol. 2017;69:122-130. doi:10.1002/art.39809

68. Furie RA, Leon G, Thomas M, et al. A phase II, randomized, placebo-controlled clinical trial of blisibimod, an inhibitor of B cell activating factor, in patients with moderate-to-severe systemic lupus erythematosus, the PEARL-SC study. Ann Rheum Dis. 2015;74:1667-1675. doi:10.1136/annrheumdis-2013-205144

69. Wallace DJ, Gordon C, Strand V, et al. Efficacy and safety of epratuzumab in patients with moderate/severe flaring systemic lupus erythematosus: results from two randomized, double blind, placebo-controlled, multicenter studies (ALLEVIATE) and follow-up. Rheumatol. 2013;52:1313-1322. doi:10.1093/rheumatology/ket129

70. Sanz I, Lee FE. B cells as therapeutic targets in SLE. Nat Rev Rheumatol. 2010;6:326-337. doi:10.1038/nrrheum.2010.68

71. Ostendorf L, Burns M, Durek P, et al. Targeting CD38 with daratumumab in refractory systemic lupus erythematosus. $N$ Engl $J$ Med. 2020;383:1149-1155. doi:10.1056/NEJMoa2023325

72. DiLillo DJ, Hamaguchi Y, Ueda Y, et al. Maintenance of long-lived plasma cells and serological memory despite mature and memory $\mathrm{B}$ cell depletion during CD20 immunotherapy in mice. J Immunol. 2008;180:361-371. doi:10.4049/jimmunol.180.1.361

73. Sorensen PS, Blinkenberg M. The potential role for ocrelizumab in the treatment of multiple sclerosis: current evidence and future prospects. Ther Adv Neurol Disord. 2016;9:44-52. doi:10.1177/ 1756285615601933

74. A study to evaluate two doses of ocrelizumab in patients with active systemic lupus erythematosus (BEGIN). Clinicaltrials.gov identifier: NCT00539838, accessed 30 August 2020. 2020.

75. A study of ocrelizumab in children and adolescents with relapsing-remitting multiple sclerosis. Clinicaltrials.gov identifier: NCT 04075266, accessed 30 August 2020. 2020.

76. A study to evaluate the efficacy and safety of ocrelizumab in adults with primary progressive multiple sclerosis (O'HAND). Clinicaltrials.gov identifier: NCT04035005, accessed 30 August 2020. 2020.

77. Reddy V, Klein C, Isenberg DA, et al. Obinutuzumab induces superior B cell cytotoxicity to rituximab in rheumatoid arthritis and systemic lupus erythematosus patient samples. Rheumatol. 2017;56:1227-1237. doi:10.1093/rheumatology/kex067

78. Montillo M, O’Brien S, Tedeschi A, et al. Autoimmune haemolytic anaemia and immune mediated thrombocytopenia in the phase III RESONATE study of Ibrutinib vs Ofatumumab in relapsed/refractory chronic lymphocytic leukemia, including a case report. Blood. 2014;124:565. doi:10.1182/blood.V124.21.5654.5654

79. Haarhaus ML, Svenungsson E, Gunnarsson I. Ofatumumab treatment in lupus nephritis patients. Clin Kidney J. 2016;9:552-555. doi:10.1093/ckj/sfw022

80. Thornton CC, Ambrose N, Ioannou Y. Ofatumumab: a novel treatment for severe systemic lupus erythematosus. Rheumatol (Oxford). 2015;54:559-560. doi:10.1093/rheumatology/keu475

81. A study to evaluate the effect of XmAb5871 on disease activity in patients with IgG4-related disease. Clinicaltrials.gov identifier: NCT 02725476, accessed 30 August 2020. 2020.

82. Vetrie D, Vorechovsky I, Sideras P, et al. The gene involved in $\mathrm{X}$ linked agammaglobulinemia is a member of the src family of protein-tyrosine kinases. Nature. 1993;361:226-233. doi:10.1038/ $361226 \mathrm{a} 0$

83. Satterthwaite AB. Bruton's Tyrosine Kinase, a component of B cell signaling pathways, has multiple roles in the pathogenesis of lupus. Front Immunol. 2018;8:1986. doi:10.3389/fimmu.2017.01986

84. Chalmers SA, Glynn E, Garcia SJ, et al. BTK inhibition ameliorates kidney disease in spontaneous lupus nephritis. Clin Immunol. 2018;197:205-218. doi:10.1016/j.clim.2018.10.008 
85. Burger JA, Tedeschi A, Barr PM, et al. Ibrutinib as initial therapy for patients with chronic lymphocytic leukemia. $N$ Engl J Med. 2015;373:2425-2437. doi:10.1056/NEJMoa1509388

86. Hutcheson J, Vanarsa K, Bashmakov A, et al. Modulating proximal cell signaling by targeting Btk ameliorates humoral autoimmunity and end-organ disease in murine lupus. Arthritis Res Ther. 2012;14: R243. doi:10.1186/ar4086.

87. MSC2364447C phase Ib in systemic lupus erythematosus. Clinicaltrials. gov identifier: NCT02537028, accessed 30 August 2020. 2020.

88. A study of AC0058TA in patients with systemic lupus erythematosus. Clinicaltrials.gov identifier: NCT03878303, accessed 30 August 2020. 2020.

89. Richardson PG, Sonnevald P, Schuster MW, et al. Bortezomib or high-dose dexamethasone for relapsed multiple myeloma. $N$ Engl $J$ Med. 2005;352:2487-2498. doi:10.1056/NEJMoa043445

90. Obeng EA, Carlson LM, Gutman DM, et al. Proteasome inhibitors induce a terminal unfolded protein response in multiple myeloma cells. Blood. 2006;107:4907-4916. doi:10.1182/blood-2005-08-3531

91. Neubert K, Meister S, Moser K, et al. The proteasome inhibitor bortezomib depletes plasma cells and protects mice with lupus-like disease from nephritis. Nat Med. 2008;14:748-755. doi:10.1038/ nm1763

92. Ichikawa HT, Conley T, Muchamuel T, et al. Beneficial effect of novel proteasome inhibitors in murine lupus via dual inhibition of type I interferon and autoantibody-secreting cells. Arthritis Rheum. 2012;64:493-503. doi:10.1002/art.33333
93. Seavey MM, Lu LD, Stump KL, et al. Novel, orally active, proteasome inhibitor, delanzomib (CEP-18770), ameliorates disease symptoms and glomerulonephritis in two preclinical mouse models of SLE. Int Immunopharmacol. 2012;12:257-270. doi:10.1016/j. intimp.2011.11.019

94. Segarra A, Arredondo KV, Jaramillo J, et al. Efficacy and safety of bortezomib in refractory lupus nephritis: a single-center experience. Lupus. 2020;29:118-125. doi:10.1177/0961203319896018

95. Alexander T, Sarfert R, Klotsche J, et al. The proteasome inhibitor bortezomib depletes plasma cells and ameliorates clinical manifestations of refractory systemic lupus erythematosus. Ann Rheum Dis. 2015;74:1474-1478. doi:10.1136/annrheumdis-2014-206016

96. Chamberlain C, Colman PJ, Ranger AM, et al. Repeated administration of dapirolizumab pegol in a randomized phase I study is well tolerated and accompanied by improvements in several composite measures of systemic lupus erythematosus disease activity and changes in whole blood transcriptomic profiles. Ann Rheum Dis. 2017;76:1837-1844. doi:10.1136/annrheumdis-2017-211388

97. Marino E, Grey ST. B cells as effectors and regulators of autoimmunity. Autoimmunity. 2012;45:377-387. doi:10.3109/ 08916934.2012 .665527

98. Louis Bridges S, White DW, Worthing AB, et al. The science behind biosimilars: entering a new era of biologic therapy. Arthritis Rheumatol. 2018. doi:10.1002/art.40388.

\section{Publish your work in this journal}

Therapeutics and Clinical Risk Management is an international, peerreviewed journal of clinical therapeutics and risk management, focusing on concise rapid reporting of clinical studies in all therapeutic areas, outcomes, safety, and programs for the effective, safe, and sustained use of medicines. This journal is indexed on PubMed Central, CAS,
EMBase, Scopus and the Elsevier Bibliographic databases. The manuscript management system is completely online and includes a very quick and fair peer-review system, which is all easy to use. Visit http://www.dovepress.com/testimonials.php to read real quotes from published authors. 